\title{
Analysis of wind data in the low atmosphere from a RASS sodar
}

\author{
I. A. Pérez, M. A. García, M. L. Sánchez, and B. de Torre \\ Department of Applied Physics, Faculty of Sciences, University of Valladolid, Valladolid, Spain \\ Received: 9 September 2004 - Revised: 9 January 2006 - Accepted: 10 January 2006 - Published: 23 March 2006
}

\begin{abstract}
This paper focuses on the ability of a sodar to describe some characteristics of the atmospheric vertical structure and presents some techniques for meteorological data evaluation. The measuring campaign took place in April 2001 and consisted of 10-min averages covering the lower atmosphere from 40 to $500 \mathrm{~m}$ at $20-\mathrm{m}$ levels. Three methods were considered, the first of which was a scalar analysis performed using a combination of wind and temperature median profiles. A noticeable contrast between day and night was obtained. Flat wind profiles during the day were a consequence of prevailing convective conditions that determined thermal turbulence. A stable layer above $260 \mathrm{~m}$ capped the unstable layer situated below and guaranteed the stability of the boundary layer. During the night, the presence of a low level jet was the most significant feature. The height of the core was $340 \mathrm{~m}$ and the higher vertical winds defined it clearly. The second method focused on the wind vector. In this analysis, the anti-cyclonic rotation of hourly averages was considered in the lower levels where it was observed. After a translation of the origin, an empirical, robust model with two parts was then proposed for the resulting vector. The angle was described linearly and the module by a second order model for cylindrical data. Finally, as a third method, three regression analyses were investigated: vectorial, taking every wind component separately and scalar. The two first seemed to be more complete due to their description of anticyclonic wind rotation when height increased. Correlation coefficients also proved to be more satisfactory. As a consequence, these techniques, although less frequently used, are more suitable to study wind in the low atmosphere.
\end{abstract}

Keywords. Meteorology and atmospheric dynamics (Turbulence; Instruments and techniques) - Radio science (Remote sensing)

\section{Introduction}

Wind analysis has become very useful not only from a theoretical point of view, but also in several fields of applied

Correspondence to: I. A. Pérez

(iaperez@fa1.uva.es) research, such as dispersion of pollutants, structures of buildings, wind energy or aerial navigation. The aim of this paper is to show how three different methods using vector or scalar data can be used to characterise the vertical structure of the lower atmosphere.

In this study, sodar data are used to describe the vertical profile of the lower atmosphere. Over the last 35 years, ground-based remote profiling of atmospheric variables has increasingly been applied, as has been described by Clifford et al. (1994) and Monna (1994). In particular, sodars have already proved to be extremely useful to investigate the internal structure of the low atmosphere in such varying contexts as urban meteorology or air flow under a wide range of orographic conditions (Argentini et al., 1999; Wölfelmaier et al., 1999; Lazar and Jernej, 2001; Anderson, 2003). The successful results of this research have been achieved thanks to the possibility of obtaining a continuous record of variables, avoiding the discrete character of soundings or the spatial limitations of masts.

The first of our objectives was to investigate the sodar's ability to obtain information from wind considered as a scalar variable. This approach is based on the clear difference observed between day and night, arising from the different nature of the boundary layer under the prevailing turbulence conditions (Kaimal and Finnigan, 1994). During the day, thermal turbulence associated with convective movements, establishes vertical mixing. During the night, however, the most noticeable feature is the presence of low level jets (Kurzeja et al., 1991). The nocturnal jets are produced by alignment between the wind mean and inertial oscillations that commence at sunset (Blackadar, 1957). The inertial oscillations are inertial gravity waves confined to the horizontal plane as they are influenced only by rotation, not by buoyancy. Inertial oscillations may be ubiquitous in the atmosphere, though with very small amplitudes. Intermittent events, such as evening transition or frontal passages, could increase their amplitudes, making them observable (Lundquist, 2003). The low level jet has been presented in the literature and some models have also been suggested (Thorpe and Guymer, 1977; Malcher and Kraus, 1983; Kraus et al., 1985; Stull, 1988; Frisch et al., 1992; Garrat, 1992; Belles, 1993; May, 1995; Blackadar, 1997; Mahrt, 1999). In

Published by Copernicus GmbH on behalf of the European Geosciences Union. 

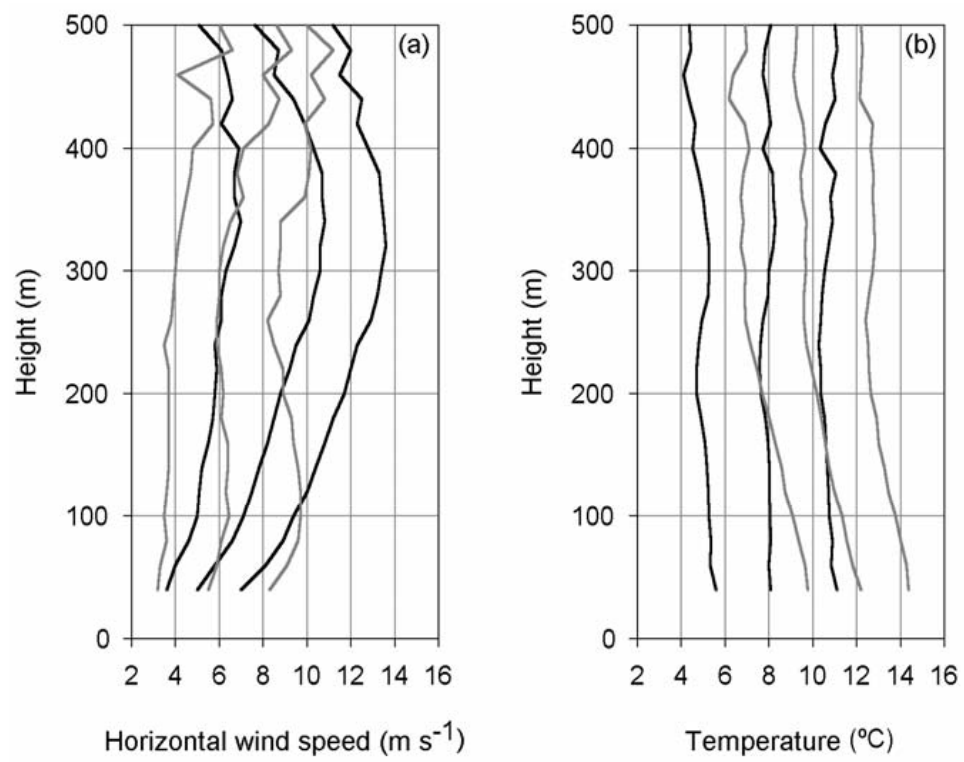

Fig. 1. First, second and third quartiles for horizontal wind speed (a) and temperature (b) during the day (from 09:00 to 17:00 UTC), in grey, and night, in black.

order to improve our vision of the low atmosphere, knowledge of thermal structure is necessary, this information being provided by a Radio Acoustic Sounding System (RASS) extension (Peters and Kirtzel, 1994).

Vector analysis was performed by means of hourly averages, a common method in climatological or sea breeze studies (Simpson, 1994; Furberg et al., 2002). Both anti-cyclonic and cyclonic evolutions have been described in the literature, the former associated with the Earth's rotation and the rest with orographic effects, differential heating and resulting synoptic-scale motions. In this kind of analysis, the sodar has the exclusive advantage of observing the vertical extension of this vector evolution. An empirical model is then proposed with the purpose of explaining wind behaviour in the lower atmosphere.

Finally, it is known that a universally accepted definition for vector correlation in geophysics does not exist. Crosby et al. (1993) have presented properties of a proposed definition for vector correlation and applied it to time series of surface marine winds at two locations in the northwest Atlantic. Kaufmann and Weber (1998) defined a simple correlation coefficient in order to explain simultaneous channelling in two valleys and used it in Switzerland. Our third analysis was a comparison of different regression techniques. Our objective is to investigate their suitability and to establish their range of application.

\section{Data description}

The equipment used in this paper is a DSDPA.90-24 sodar equipped with a RASS extension and built by
Meteorologische Messtechnik (METEK) GmbH. It was installed at the Centro de Investigación de la Baja Atmósfera (CIBA), $41^{\circ} 49^{\prime} 2^{\prime \prime} \mathrm{N}, 4^{\circ} 56^{\prime} 15^{\prime \prime} \mathrm{W}$, about $30 \mathrm{~km}$ northwest of Valladolid (Spain). The location is an extensive plateau $840 \mathrm{~m}$ above MSL, which does not present relief elements at more than $10 \mathrm{~km}$ around the measuring point, except in the northwest sector, where the plain extends up to $5 \mathrm{~km}$. Hence, we can assume horizontal homogeneity. For this reason, orographic influences on the temporal evolution of the boundary layer vertical structure are excluded. Non-irrigated crops, like cereals, make up the surrounding vegetation.

The measuring period considered in this paper was the month of April 2001. This was a short enough interval to avoid annual trends and long enough to provide a representative number of data. A summary of the synoptic situation during this period is described in Pérez et al. (2004). The equipment worked correctly and interruptions were below $0.8 \%$ and were attributable to electric cutoffs not related to the device. Ten-min averages were considered. The minimum height was $40 \mathrm{~m}$ and the maximum $500 \mathrm{~m}$, and a $20-\mathrm{m}$ vertical resolution was used.

The files yielded plenty of information, although in the present analysis only wind speed and temperature were considered. The data were subjected to the quality control suggested by the manufacturer that consisted of rejecting those observations whose signal-noise ratio was below $-3 \mathrm{~dB}$.

This database has been used in previous papers. The number of available (valid) data, determined by their signalnoise ratio, showed a strong influence with height. At $40 \mathrm{~m}$, nearly all the data recorded are valid. However, at $500 \mathrm{~m}$, the availability of data was slightly below $4 \%$ for the sodar and above $20 \%$ for the RASS. Vertical profiles of wind speed 


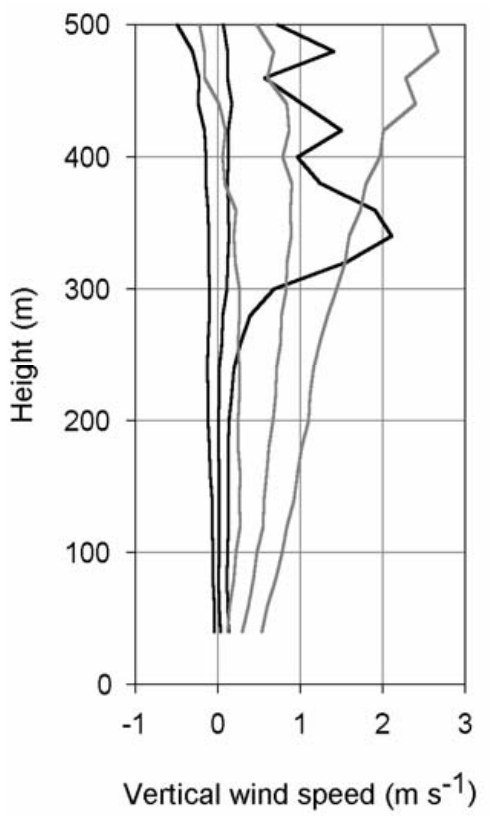

Fig. 2. First, second and third quartiles for vertical wind speed during the day (in grey) and night (in black).

and temperature were also studied. Initial inspection of the data showed that the boundary layer presented a well-defined structure with a daily evolution. The median wind speed profile in the lowest $200 \mathrm{~m}$ was an exponential profile during the night. During the day, from 09:00 to 17:00 UTC, convection caused nearly flat profiles. However, the profile of the temperature median was linear during the day and early hours of the night, due to soil heating. Outside of this period, nocturnal stable stratification was dominant (Pérez et al., 2003).

\section{Methodology and results}

\subsection{Scalar analysis}

The daily cycle was divided into two periods, day and night, defined by the analysis of the hourly evolution of the wind speed profile cited in Sect. 2. Figure 1 shows the first, second and third quartiles for wind speed and temperature in both periods, night in black and day in grey. Smooth curves were obtained below $400 \mathrm{~m}$, although above this level, low availability made the effects of possible outliers dominant, resulting in sharp contrasts between adjacent levels. Consequently, any conclusion involving these levels seemed risky and should be avoided.

The diurnal wind speed profile was nearly flat due to turbulent eddies derived from convection originating in the heating of the lower layers where thermal turbulence was more relevant. The temperature profile showed this situation below $260 \mathrm{~m}$, though a stable layer was located above. Contrasting

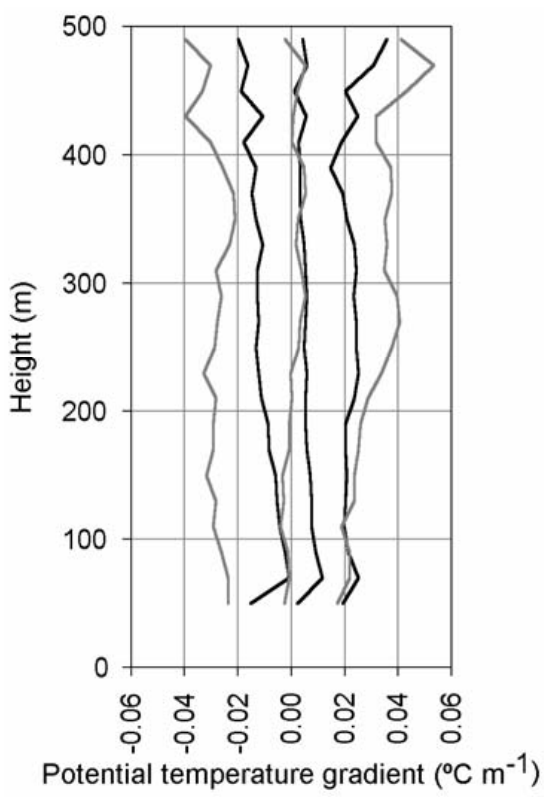

Fig. 3. First, second and third quartiles of potential temperature gradient during the day (in grey) and night (in black).

behaviour was observed during the night. Wind speed values were lower near the ground due to surface friction, although a nocturnal jet was observed with a maximum wind speed at $340 \mathrm{~m}$ favoured by stable stratification, forcing horizontal movements. It is worth highlighting the existence of a stable layer above $260 \mathrm{~m}$ during the whole time which guaranteed the persistence of the boundary layer structure. In general, winds were faster during the night, determining an oscillatory daily evolution. As a marginal result, a contrast between day and night was perceived at 40-m height where the lower speeds, corresponding to the first quartile, observed during the day were followed by greater values during the night and the behaviour was opposite with the higher speeds, corresponding to the third quartile.

Vertical wind speed is presented in Fig. 2. Its values are one order of magnitude lower than the horizontal ones. The median was very weak at night, and the most noticeable feature was the maximum of the third quartile at the height of the core of the nocturnal jet, which had a well-defined vertical extension through this variable. Moreover, these vertical wind speeds were not symmetrical with regard to the maximum axis. This shape implied divergence processes in the higher vertical wind speeds at this level whose origin was the strong horizontal winds. By contrast, the median increased continuously with height during the day. This result was the experimental evidence of convective movements that transported relatively warm air from the ground to more distant levels and as a consequence the temperature profile showed the stable layer previously described. 

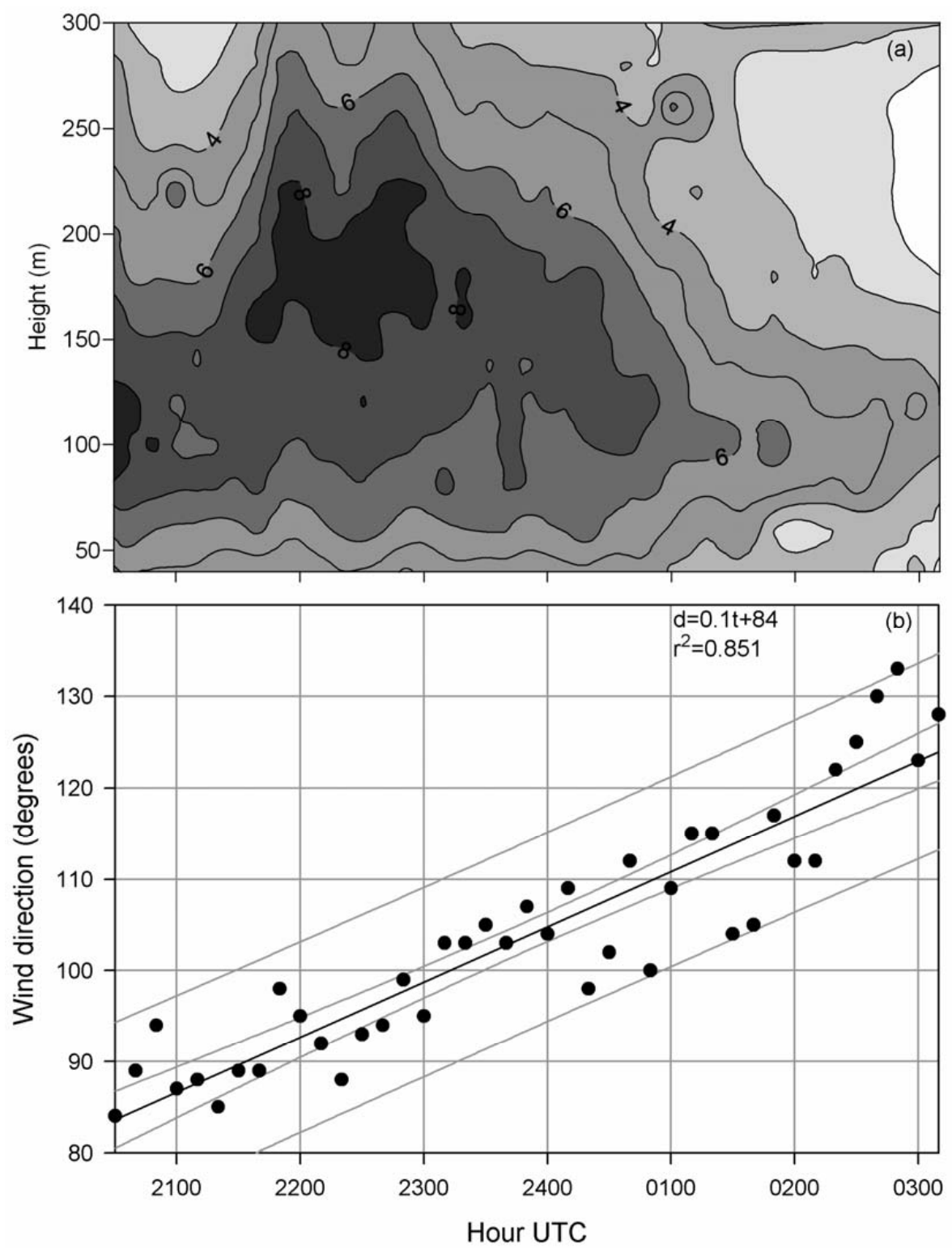

Fig. 4. Low level jet observed from 8 to 9 April 2001; (a) shows the time evolution of wind speed. The low height of the maxima is the most noticeable feature; (b) is the linear fitting of wind direction in the jet core. Confidence and prediction limits are drawn in grey.

The potential temperature vertical gradients were calculated from the temperature difference between adjacent levels followed by a $0.0098^{\circ} \mathrm{C} \mathrm{m}^{-1}$ addition (Arya, 2001). Medians and quartiles were then calculated for diurnal and nocturnal periods and presented in Fig. 3. Three regions may be established looking at medians:

1. A stable layer above $250 \mathrm{~m}$ was present during the whole time.

2. There was a slightly unstable layer between 70 and $250 \mathrm{~m}$ during the day but stable during the night. Due to this oscillatory behaviour, this layer against the one previously presented may be considered in some way decoupled.

3. A trend towards instability appeared at lower heights, below $70 \mathrm{~m}$. This layer would be integrated in the layer located on it during the day, but it would be a surface residual layer during the night.

The interquartile range was wider during the day, due to the presence of active turbulence and accentuated contrasts between adjacent levels.

As a conclusion, the movements inside the stable layer should be horizontal mainly during the night when 


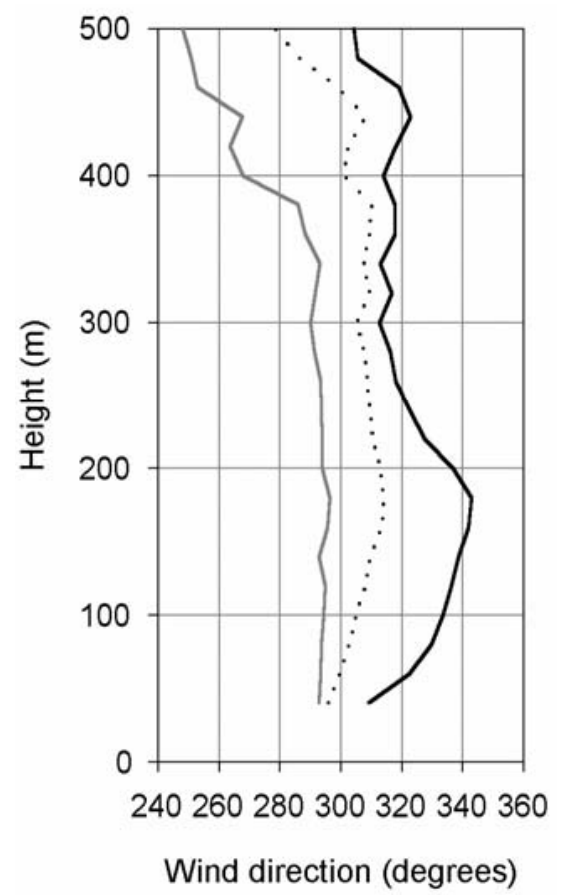

Fig. 5. Resulting direction calculated by average of unit vectors. The dotted line corresponds to the whole day, black line for the night and grey line for the day.

convection is not present. In this situation, the development of nocturnal jets was guaranteed. However, surface friction slowed down air movement as height decreased.

In order to extract any additional information about nocturnal jets, we followed a selection procedure according to Andreas et al. (2000), which identified a low level jet when the local maximum is $2 \mathrm{~m} \mathrm{~s}^{-1}$ higher than speeds both above and below it. A total of 265 10-min profiles were selected, and although the persistence of these jets proved highly irregular, some lasted a considerably long time. Percentile 80 corresponded to a core height of $300 \mathrm{~m}$ and a wind speed of $15 \mathrm{~m} \mathrm{~s}^{-1}$. Figure $4 \mathrm{a}$ shows a jet observed from 8 to 9 April for a duration of over $6 \mathrm{~h}$. In this case, the maximum wind speed in the core was about $9 \mathrm{~m} \mathrm{~s}^{-1}$ followed by a continuous decrease. This low speed agreed with the core height, which was relatively near the ground, always below $200 \mathrm{~m}$ and at $100 \mathrm{~m}$ for two hours (i.e. nearly one-third of its duration). The wind direction turned anti-cyclonically. It was successfully fitted by means of a linear regression that provided a constant rate of six degrees turned per hour (Fig. 4b). Damped inertial oscillations appearing in the evening transition seemed to be the most reasonable explanation since there is neither relief, nor slope and the large-scale circulation was dominated by a high-pressure system during these couple of days.

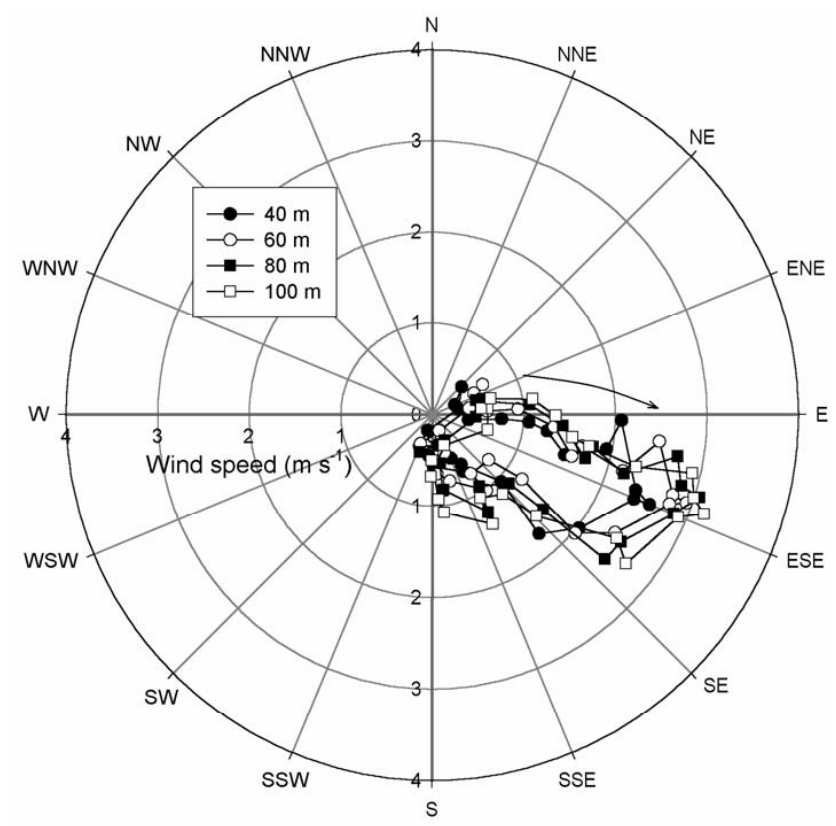

Fig. 6. Anti-cyclonic rotation of the hourly average wind speed in the first four levels.

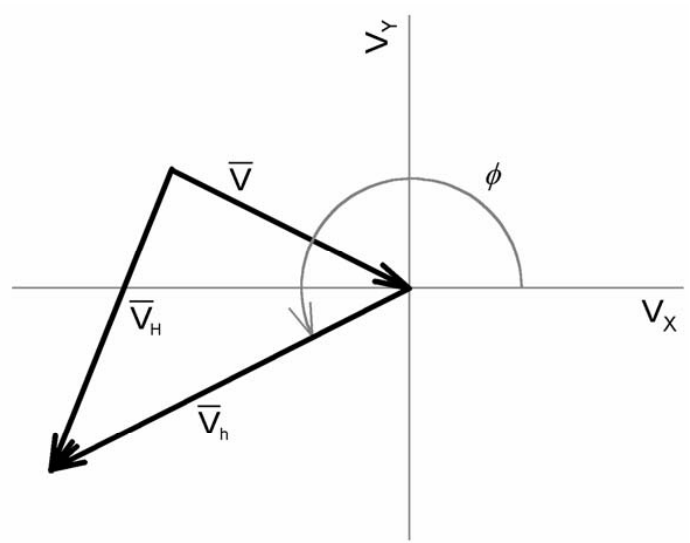

Fig. 7. Translation of coordinates so as to observe more clearly wind rotation in the low atmosphere. $\overline{\boldsymbol{V}}$ is the global average, $\overline{\boldsymbol{V}}_{\boldsymbol{H}}$, the hourly average and $\bar{V}_{\boldsymbol{h}}$ the difference between them.

\subsection{Wind vector}

The easiest way to study wind direction as a separate variable is to consider it as a unit vector. This method is common when working with circular data (Fisher, 1993; Borradaile, 2003) and was already used successfully for wind data though in a different context by Klink (1998) (Fig. 5). Using this method, we can show that the wind direction profile was nearly flat below $340 \mathrm{~m}$ and nocturnal values were turned to the right. This behaviour was especially visible at $180 \mathrm{~m}$. 

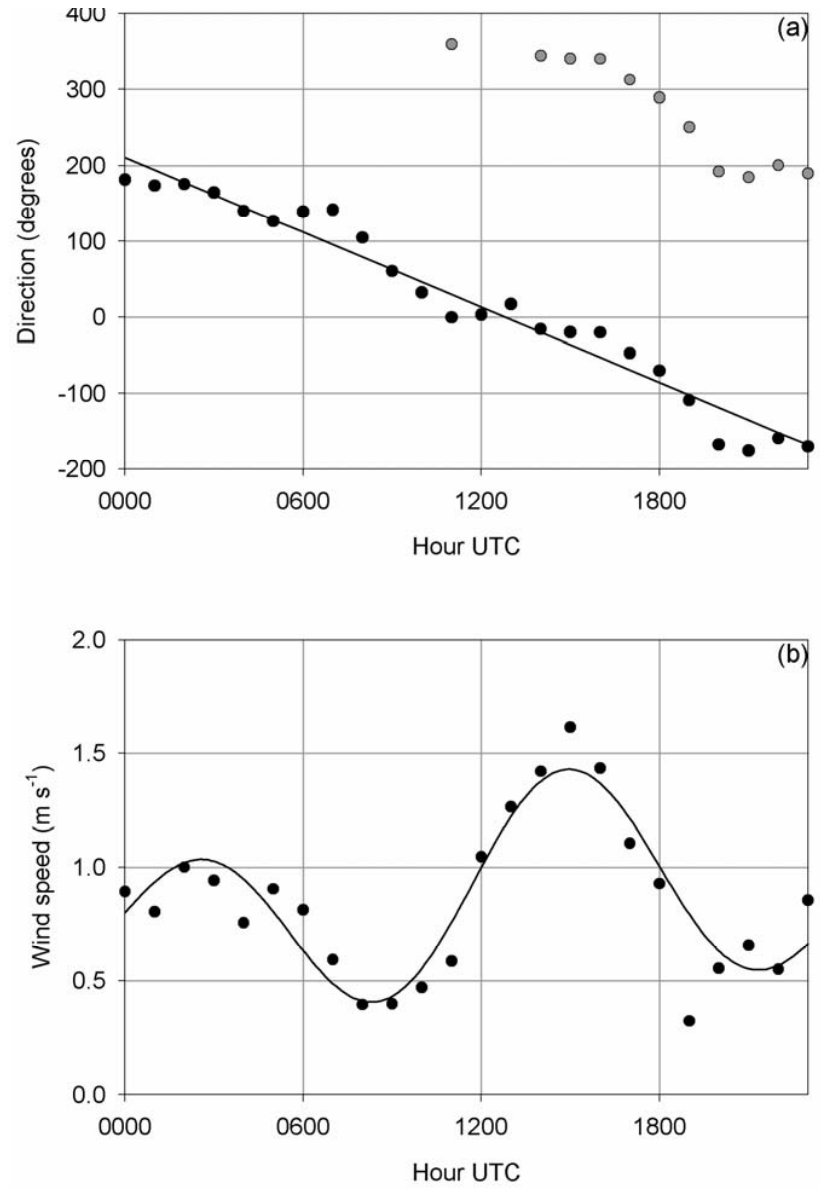

Fig. 8. (a) Daily evolution of the direction $\phi$ in the lowest level $(40 \mathrm{~m})$. Initial values were positive, although the gap was avoided by subtracting $360^{\circ}$. After this transformation the trend was linear, turning anti-cyclonically. (b) Daily evolution of $\left|\overline{\boldsymbol{V}}_{\boldsymbol{h}}\right|$ in the lowest level fitted by a second order model for cylindrical data.

The hourly evolution of the wind vector is represented in Fig. 6, where the hodograph of hourly average wind vectors is depicted for the four lower levels. An anti-cyclonic rotation was evident, although this cycle was only visible below $200 \mathrm{~m}$. An attempt was made to build an empirical model to describe this behaviour. Firstly, the origin of the coordinates was changed to enable observation of the movement in a simpler way (Kusuda and Alpert, 1983). $\overline{\boldsymbol{V}}_{\boldsymbol{h}}$ were differences between the wind vector hourly average values, $\bar{V}_{\boldsymbol{H}}$, and the global average values, $\overline{\boldsymbol{V}}$, for each height level, according to the diagram presented in Fig. 7. Polar coordinates were selected to split the process into two separate evolutions: one for the module of $\overline{\boldsymbol{V}}_{\boldsymbol{h}}$ and another for the argument $\phi$.

A gap in the temporal evolution argument was observed when 00:00 UTC was taken as a starting point. For this reason, a subtraction of $360^{\circ}$ was calculated when the angular distance between two consecutive values was greater

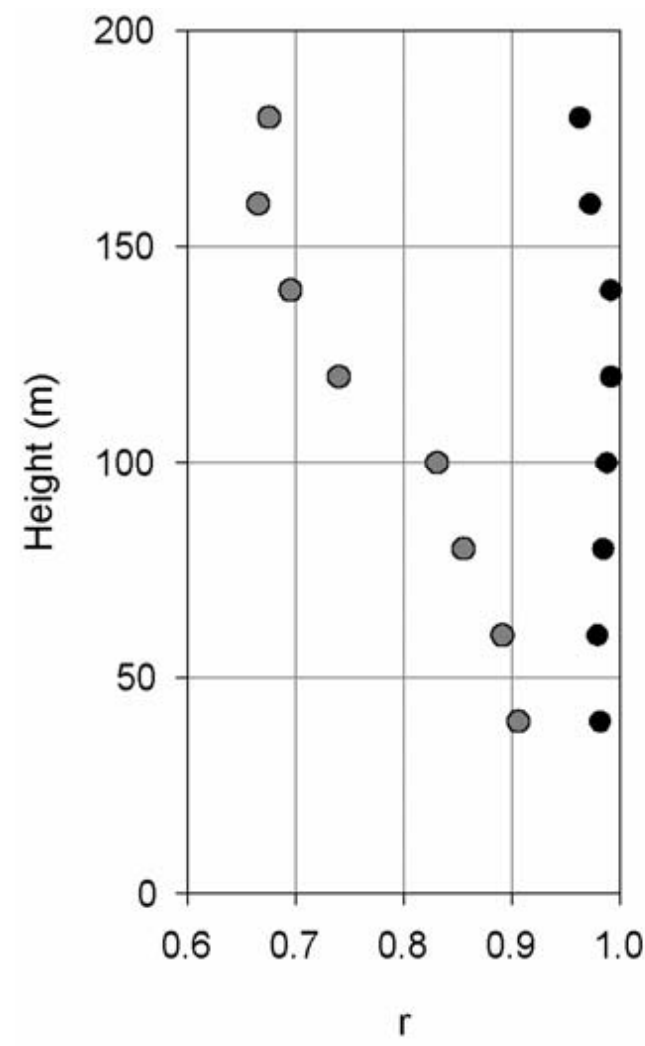

Fig. 9. Pearson correlation coefficients calculated between experimental and modelled modules (in grey) and arguments of $\overline{\boldsymbol{V}}_{\boldsymbol{h}}$ (in black).

than $180^{\circ}$. Figure 8 a presents this procedure for the lowest level $(40 \mathrm{~m})$ where the first half of the points exhibited a decreasing trend, but a sharp contrast with the second half. As a consequence, negative values appeared, although a linear trend was attained. A weighted linear regression was then performed. This is an iterative procedure that makes this analysis more robust by using a weight function that reduces outlier influence. In our case, the bisquared "bump" function, successfully used by Cleveland (1993), was selected:

$w(\gamma)=\left\{\begin{array}{cc}\left(1-\gamma^{2}\right)^{2}-1 \leq \gamma \leq 1 \\ 0 & \text { rest }\end{array}\right.$

with

$\gamma=\frac{r}{6 s}$,

where $r$ is every absolute residual and $s$ their median. A difference between two consecutive medians lower than $1 \%$ was used as a convergence criterion. This resulted in a low number of iterations. Slopes were close to $-16 \mathrm{deg} \mathrm{h}^{-1}$ and intercepts to $210 \mathrm{deg}$. As a result, a continuous anti-cyclonic rotation was obtained that was very close to the theoretical value of $-15 \mathrm{deg} \mathrm{h}^{-1}$, corresponding to the daily cycle. Pearson correlation coefficients between corrected and calculated 
values are presented as black points in Fig. 9 to quantify the goodness of fits. Satisfactory and height independent relationships are concluded.

The evolution of $\left|\overline{\boldsymbol{V}}_{\boldsymbol{h}}\right|$ in the lowest level is depicted in Fig. 8 b, where a contrast between day and night became evident. The daily maximum produced by thermal and mechanical turbulence was more important than the nocturnal one, when stable stratification softened mechanical turbulence. The transition between both periods was marked by minima, especially in the morning, when the mixing layer began its continuous development, whereas the transition to the night is sharper. This behaviour determined the selection of a second order model for cylindrical data (AndersonCook, 2000). An important feature of the model is its ability to provide a good description of a cyclical variable with two maxima. The model is given by:

$y=b_{0}+a_{1} \cos \left(\delta-\delta_{01}\right)+a_{2} \cos \left(2 \delta-\delta_{02}\right)$

$\delta_{01}, \delta_{02} \in[0,2 \pi)$.

The response $(y)$ and angle $(\delta)$ variables in our application are the differences between the hourly wind vector averages and the global average value $\left(\left|\overline{\boldsymbol{V}}_{\boldsymbol{h}}\right|\right)$ and the angle changing with time $(\phi)$ respectively. The coefficient calculation was made by a weighted multiple linear regression with the same weight function as was previously presented in Eqs. (1) and (2). The initial expression was:

$\mathbf{y}=\mathbf{X b}$,

where $\mathbf{y}$ is the matrix of the response variable and the matrices $\mathbf{X}$ and $\mathbf{b}$ are:

$\mathbf{X}=\left(\begin{array}{ccccc}1 & \cos \left(\delta_{1}\right) & \sin \left(\delta_{1}\right) & \cos \left(2 \delta_{1}\right) & \sin \left(2 \delta_{1}\right) \\ 1 & \cos \left(\delta_{2}\right) & \sin \left(\delta_{2}\right) & \cos \left(2 \delta_{2}\right) & \sin \left(2 \delta_{2}\right) \\ \ldots & \ldots & \ldots & \ldots & \ldots \\ 1 & \cos \left(\delta_{k}\right) & \sin \left(\delta_{k}\right) & \cos \left(2 \delta_{k}\right) & \sin \left(2 \delta_{k}\right)\end{array}\right) ; \mathbf{b}=\left(\begin{array}{l}b_{0} \\ b_{1} \\ b_{2} \\ b_{3} \\ b_{4}\end{array}\right)$,

where $k$ is the data number. The weighted coefficients can then be calculated by means of the diagonal matrix $\mathbf{W}$ containing the weights and the $\mathbf{X}$ matrix transposed, $\mathbf{X}^{\mathrm{T}}$ :

$\mathbf{b}_{\mathbf{w}}=\left(\mathbf{X}^{\mathrm{T}} \mathbf{W} \mathbf{X}\right)^{-1} \mathbf{X}^{\mathrm{T}} \mathbf{W} \mathbf{y}$.

The weighted coefficients to introduce into Eq. (3) may then be obtained from:

$a_{1}=\sqrt{b_{1 W}^{2}+b_{2 W}^{2}} ; \quad \tan \delta_{01}=\left(\frac{b_{2 W}}{b_{1 W}}\right) ;$
$a_{2}=\sqrt{b_{3 W}^{2}+b_{4 W}^{2}} ; \quad \tan \delta_{02}=\left(\frac{b_{4 W}}{b_{3 W}}\right)$.

The function fitted was also depicted in Fig. 8b. Although the agreement was in general good, a slight decrease was observed with height for the Pearson correlation coefficient (Fig. 9) that may be attributed to experimental reasons. The contrast between day and night changed when height increased and the model proved more limited in these levels.

\subsection{Regression analyses}

Wind measurements are usually recorded at low values of height. However, in some analyses, such as for wind energy purposes, measurements at higher levels are desirable. For this reason our third objective was to investigate the relationship between wind values at the lowest elevation level and the other levels. For this objective, three different regression methods were evaluated.

\subsubsection{Vector regression}

The vector correlation method presented by Hanson et al. (1992) was initially selected due to its completeness. The correlation coefficient is defined in this method by a direct analogue to scalar correlation and has the same range, but in this case +1 implies a perfect rotational relationship, -1 implies a perfect reflectional relationship and zero implies completely uncorrelated data with respect to both types of relationships. The regression equation is:

$w_{j}=\beta z_{j}+\alpha$,

where $\boldsymbol{w}$ and $\boldsymbol{z}$ are two dimensional vectors and the subscript represents one particular observation. The vector coefficients $\boldsymbol{\beta}$ and $\boldsymbol{\alpha}$ may be written as:

$\boldsymbol{\beta}=B e^{i \Theta} ; \quad \boldsymbol{\alpha}=A e^{i \theta}$,

where $B$ is a scale factor and $\Theta$ an angle for rotation or reflection whereas $\boldsymbol{\alpha}$ represents a translation of coordinates. The technique is not common, although a successful application of the method was shown by Ekström (2002). The main advantage of this analysis is the ability to determine the height range where translation or rotation from the lowest level is prevalent. Figure 10 shows the results for the different parameters. The translation had minor importance below $200 \mathrm{~m}$. A sharp contrast between day and night was observed around $300 \mathrm{~m}$ for $A$, and $\theta$ showed no noticeable differences for both periods above $300 \mathrm{~m}$. Scale factor $B$ was close to one during the day, decreasing slightly with height to compensate for the increase in $A$. However, this factor increased continuously up to $200 \mathrm{~m}$ during the night and remained nearly constant around 1.5 above this level up to $380 \mathrm{~m}$. A rotation was obtained and the anti-cyclonic (negative) turning angle, $\Theta$, increased slowly up to $13^{\circ}$ at $400 \mathrm{~m}$ during the night. No noticeable rotation was observed during the day. The values for the whole day were closer to the nocturnal ones, due to the greater weight of this period. The correlation coefficient, $r_{1}$ (Fig. 13a), decreased slowly with height and showed slight differences between day and night below $300 \mathrm{~m}$. Correlations were higher during the night above this level due to the well-defined nocturnal wind pattern at this layer. Finally, the fall of the correlation coefficient at higher heights may indicate a more complex relationship than the proposed linear one. 

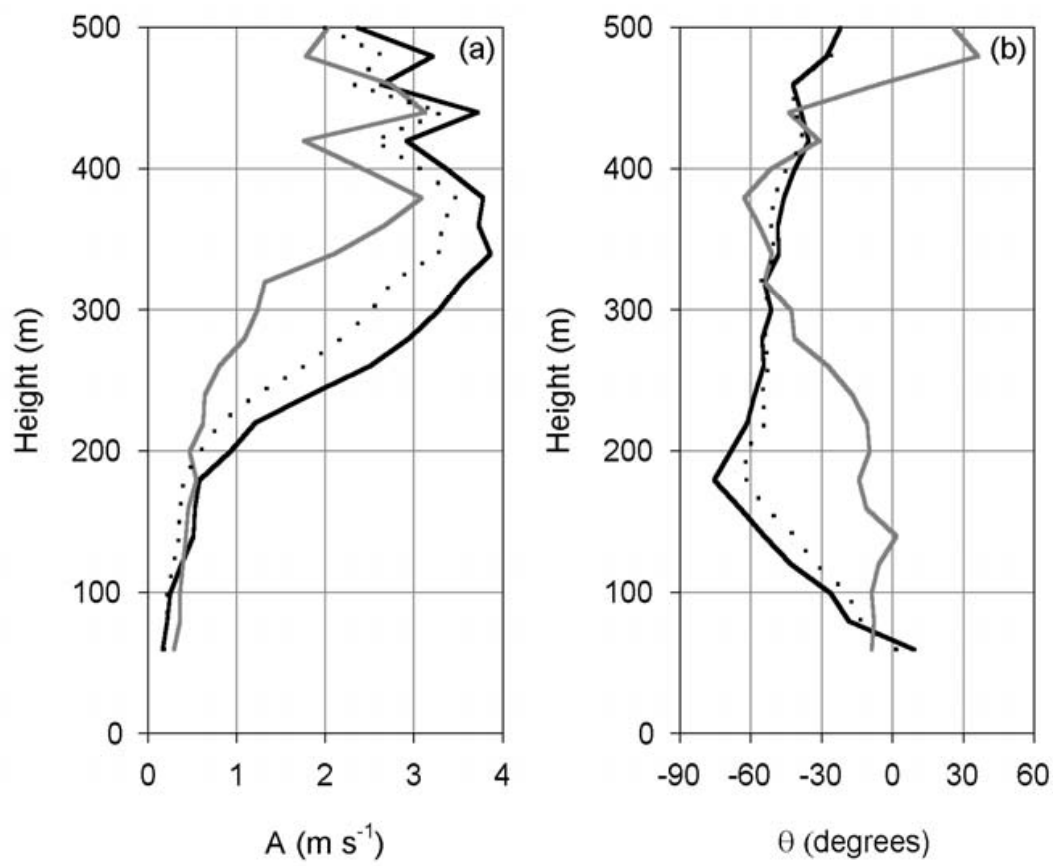

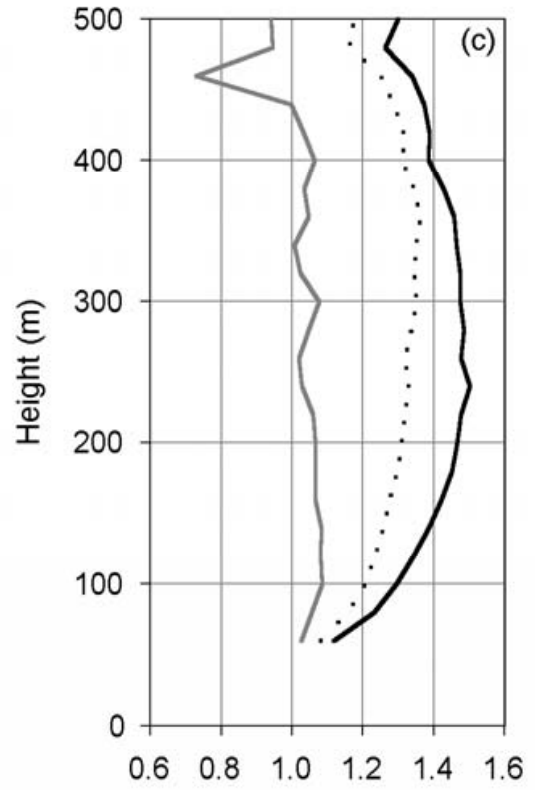

B

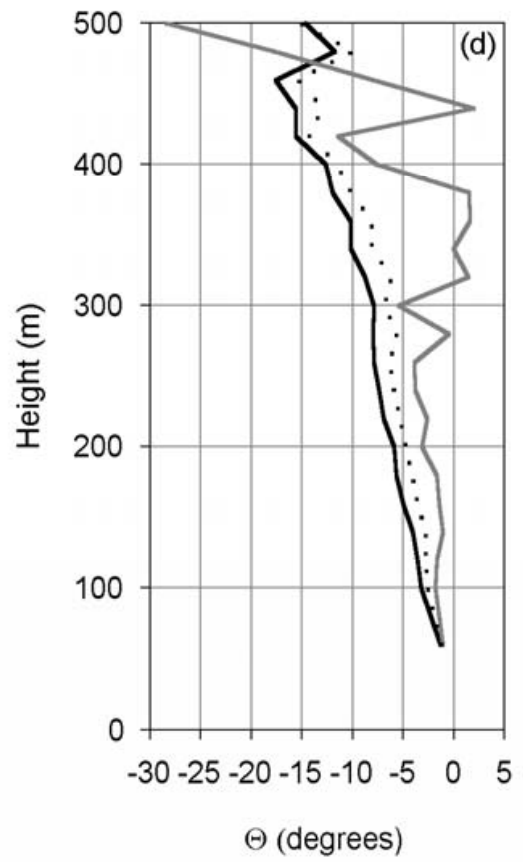

Fig. 10. Change with height for different parameters corresponding to vector correlation, dotted line for the global data, in black for the night and in grey for the day.

\subsubsection{Regression of each wind component}

Following Achberger et al. (2002), regressions for each wind component were calculated. The equations for this method are:

$w_{X j}=a_{X}+b_{X} z_{X j} ; \quad w_{Y j}=a_{Y}+b_{Y} z_{Y j}$ where subscripts correspond to each component. The results for slopes are presented in Fig. 11; the translation parameters are not depicted, since they were nearly the same as for the method previously presented. Below $200 \mathrm{~m}$ the slopes increased continuously during the night and were flat during the day, whereas above this level they were relatively constant with height and intercepts were the parameters 

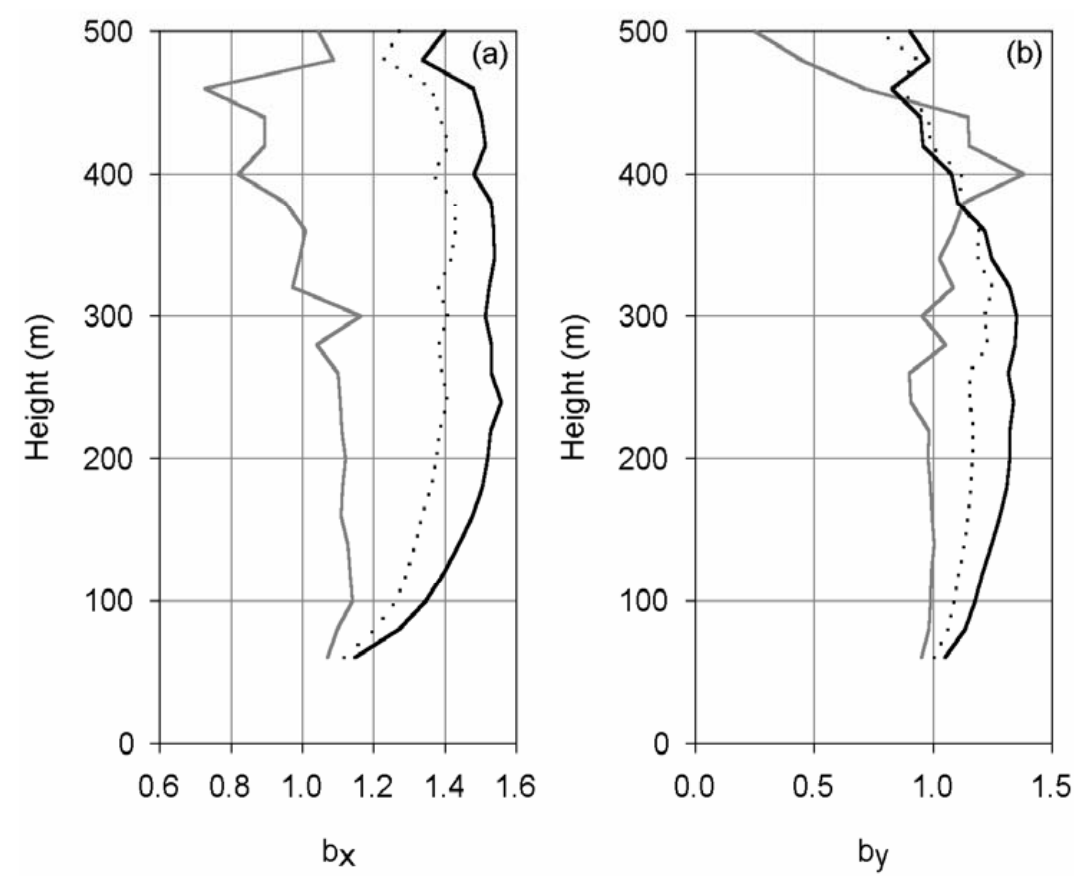

Fig. 11. Parameters calculated for the regression of wind components, dotted line for the global data, in black for the night and in grey for the day.
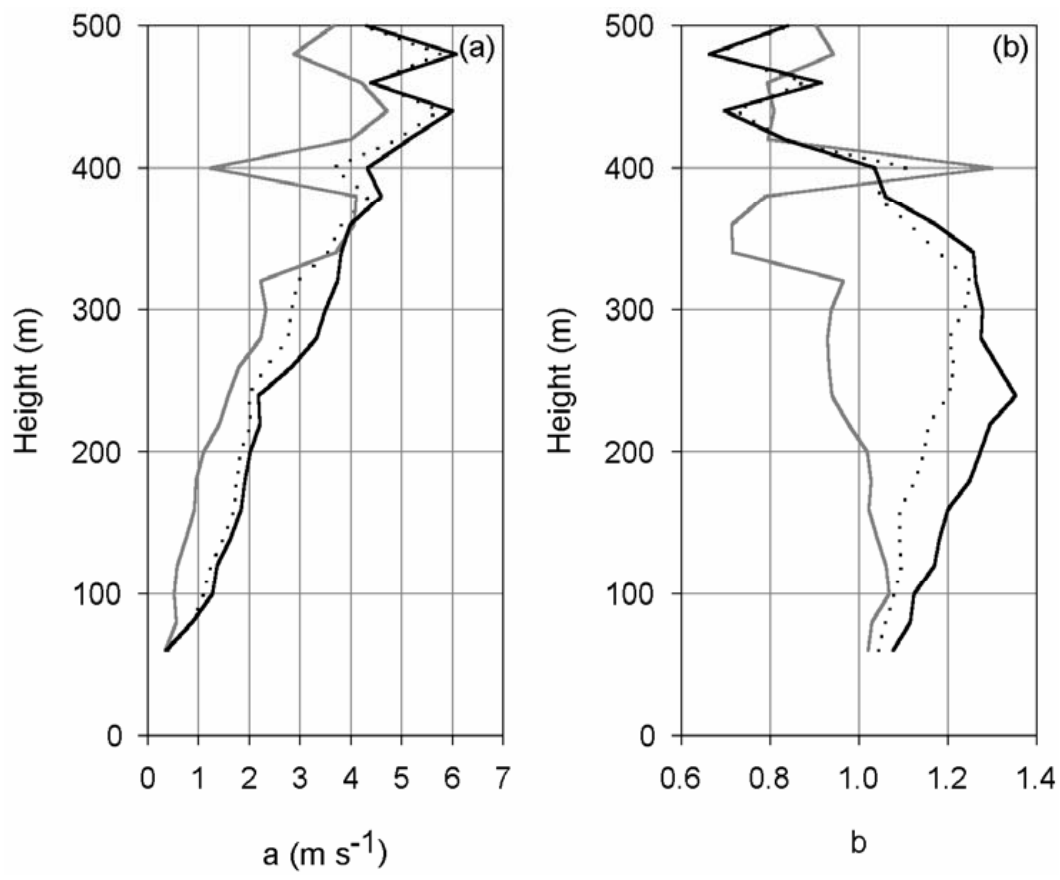

Fig. 12. Parameters corresponding to scalar regression, dotted line for the global data, in black for the night and in grey for the day.

responsible for the height variation of the wind speed. The correlation coefficients, $r_{2 X}$ and $r_{2 Y}$ (Figs. 13b and c), decreased continuously with height, particularly for the y-component. No difference for this parameter was seen between day and night for the y-component correlation and for the $\mathrm{x}$-component correlation below $300 \mathrm{~m}$. 

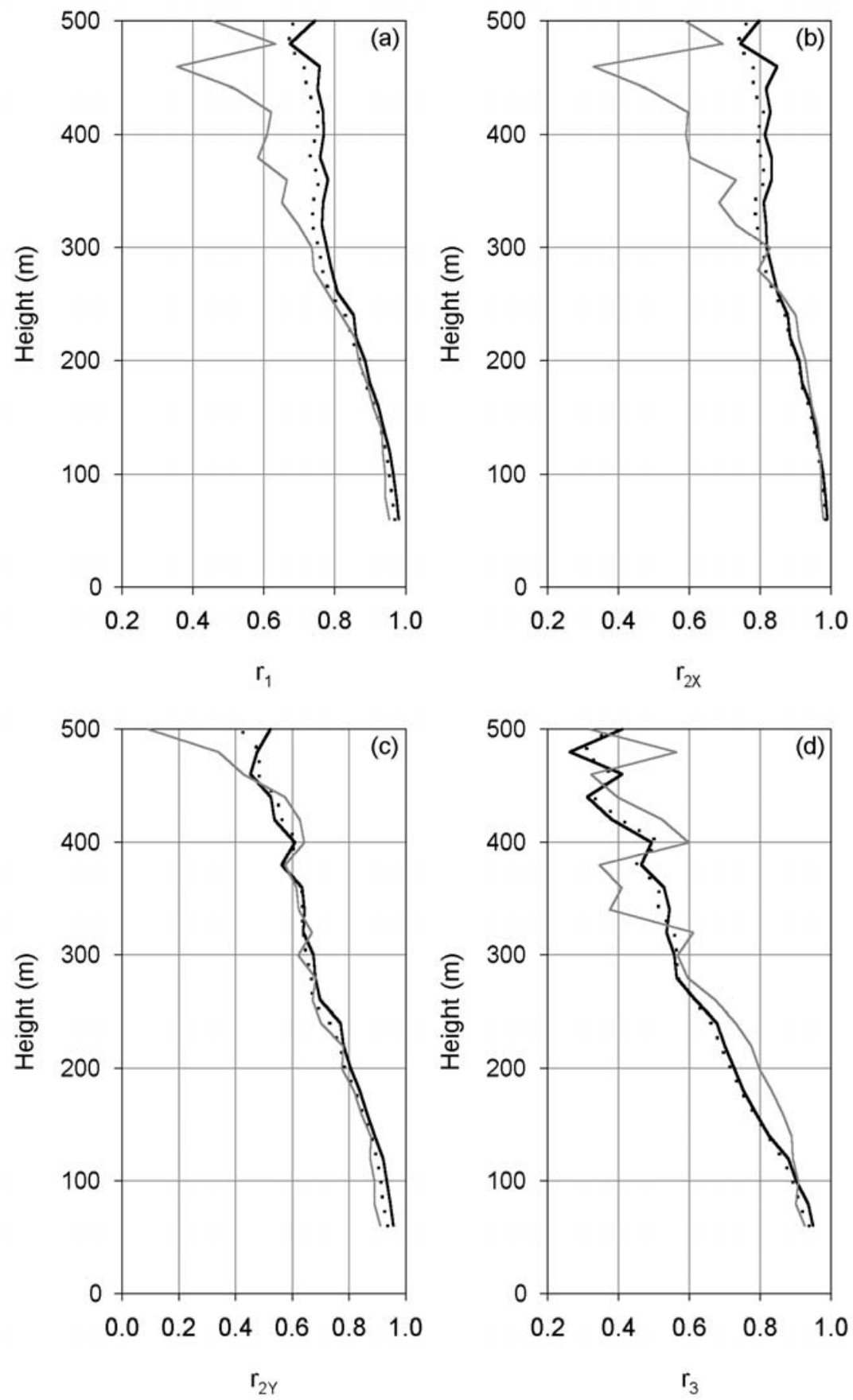

Fig. 13. Correlation coefficients calculated for the three methods considered above: (a) vector correlation, (b) and (c) correlation of wind components and (d) scalar correlation, dotted line for the global data, in black for the night and in grey for the day.

\subsubsection{Scalar regression}

Figure 12 shows the results for this situation when only the module of the wind vector was considered. The intercept $a$ increased continuously. Noticeable differences between day and night were only observed in the slope $b$, which decreased with height during the day and increased during the night. Finally, the correlation coefficient, $r_{3}$ (Fig. 13d), fell faster than in the two methods considered above. This result suggested avoiding this last procedure which ignored the vector character of the wind and selecting one of the previously described. 


\section{Conclusions}

Three analyses of wind were performed in the low atmosphere (below $500 \mathrm{~m}$ height) by using 10-min averages from data obtained with a RASS sodar during April 2001. The first was scalar analysis and connected with the thermal structure of the low atmosphere. The second was an analysis of the wind vector in the layer closer to the ground and the third, a comparison of regression methods.

The analysis of wind and temperature profiles enabled us to identify daytime and nighttime structures of the lower atmosphere. During the day, a stable layer was observed above $260 \mathrm{~m}$, which capped the unstable layer below. In the unstable layer, vertical movements were caused mainly by convection. The suppression of vertical movements in the lower atmosphere during nighttime enabled the development of low level jet streams. A noticeable maximum in the higher vertical wind speeds was evident at core height.

Analysis of the wind vector showed that the wind direction in the low atmosphere turns anti-cyclonicly. In order to describe this behaviour in a simplified way, hourly averages were considered as a combination of two parts, the first being the wind average and the second described by a rotating vector. An empirical model was then proposed for the second part. Angles showed a linear dependence with time, implying evolution at a constant rate. This result is proof of the suitability of our model. Modules were parameterised by a second order model for cylindrical data which successfully described their daily evolution where two minima were reached, the first at the beginning of the development of the mixing layer and the second at the moment of its destruction. Two maxima were also present: the highest during the day due to turbulence conditions; during the night the stable stratification led to a second maximum with lower speeds.

Finally, three regression analyses were performed, taking the lowest level as a reference. Vector correlation accounted for wind vectors as a product by a factor and a rotation followed by a translation. Anti-cyclonic rotation increased with height due to the lower influence of the surface at higher levels. This analysis has also revealed the low influence of translation below $200 \mathrm{~m}$. Correlation of the two components of the wind speed was in some way similar to the previous analysis, although this formulation seemed less complete. Slopes calculated in this analysis showed the contrast between day and night for wind speed profiles. Correlation coefficients were satisfactory in both methods. Scalar correlation was also investigated, although correlation coefficients were lower than the preceding ones, indicating this technique to be less suitable. It should be therefore avoided and replaced by one of those previously presented.

Acknowledgements. The authors wish to acknowledge the financial support from the Interministerial Commission of Science and Technology and the Regional Government of Castile and Leon.

Topical Editor O. Boucher thanks two referees for their help in evaluating this paper.

\section{References}

Achberger, C., Ekström, M., and Bärring, L.: Estimation of local near-surface wind conditions - a comparison of WASP and regression based techniques, Meteorol. Appl., 9, 211-221, 2002.

Anderson, P. S.: Fine-scale structure observed in a stable atmospheric boundary layer by sodar and kite-borne tethersonde, Bound.-Layer Meteor., 107, 323-351, 2003.

Anderson-Cook, C. M.: A second order model for cylindrical data, J. Statist. Comput. Simul., 66, 51-65, 2000.

Andreas, E. L., Claffey, K. J., and Makshtas, A. P.: Low-level atmospheric jets and inversions over the western Weddell Sea, Bound.-Layer Meteor., 97, 459-486, 2000.

Argentini, S., Mastrantonio, G., and Lena, F.: Case studies of the wintertime convective boundary-layer structure in the urban area of Milan, Italy, Bound.-Layer Meteor., 93, 253-267, 1999.

Arya, P. S.: Introduction to Micrometeorology, Academic Press, San Diego, 2001.

Belles, J.: The nocturnal jet, Iowa Technical Journal, 1, 4-8, 1993.

Blackadar, A. K.:Boundary layer wind maxima and their significance for the growth of the nocturnal inversions, Bull. Amer. Meteorol. Soc., 38, 283-290, 1957.

Blackadar, A. K.: Turbulence and Diffusion in the Atmosphere, Springer-Verlag, Berlin, 1997.

Borradaile, G. M.: Statistics of Earth Science Data, SpringerVerlag, Berlin, 2003.

Cleveland, W. S.: Visualizing Data, Hobart Press, Summit, 1993.

Clifford, S. F., Kaimal, J. C., Lataitis, R. J., and Strauch, R. G.: Ground-based remote profiling in atmospheric studies: an overview, Proc. IEEE, 82, 313-355, 1994.

Crosby, D. S., Breaker, L. C., and Gemmill, W. H.: A proposed definition for vector correlation in geophysics: theory and application. J. Atmos. Oceanic Technol., 10, 355-367, 1993.

Ekström, M.: Estimating monthly surface winds for Scania, southern Sweden, using geostrophic wind (1899-1997), Geogr. Ann., 84A, 113-126, 2002.

Fisher, N. I.: Statistical Analysis of Circular Data, Cambridge University Press, Cambridge, 1993.

Frisch, A. S., Orr, B. W., and Martner, B. E.: Doppler radar observations of the development of a boundary layer nocturnal jet, Mon. Wea. Rev., 120, 3-16, 1992.

Furberg, M., Steyn, D. G., and Baldi, M.: The climatology of sea breezes on Sardinia, Int. J. Climatol., 22, 917-932, 2002.

Garrat, J. R.: The Atmospheric Boundary Layer, Cambridge University Press, Cambridge, 1992.

Hanson, B., Klink, K., Matsuura, K., Robeson, S. M., and Willmott, C. J.: Vector correlation: review, exposition, and geographic application, Ann. Assoc. Am. Geogr., 82, 103-116, 1992.

Kaimal, J. C. and Finnigan, J. J.: Atmospheric Boundary Layer Flows, Oxford University Press, Oxford, 1994.

Kaufmann, P. and Weber, R. O.: Directional correlation coefficient for channeled flow and application to wind data over complex terrain, J. Atmos. Oceanic Technol., 15, 89-97, 1998.

Klink, K.: Complementary use of scalar, directional and vector statistics with an application to surface winds, Prof. Geogr., 50, 3-13, 1998.

Kraus, H., Malcher, J., and Schaller, E.: A nocturnal low level jet during PUKK. Bound.-Layer Meteor., 31, 187-195, 1985.

Kurzeja, R. J., Berman, S., and Weber, A. H.: A climatological study of the nocturnal planetary boundary layer, Bound.-Layer 
Meteor., 54, 105-128, 1991.

Kusuda, M. and Alpert, P.: Anti-clockwise rotation of the wind hodograph. Part I: theoretical study, J. Atmos. Sci., 40, 487-499, 1983.

Lazar, R. and Jernej, S.: First results of the urban climate analysis of Ljubljana, Meteor. Z., 10, 273-276, 2001.

Lundquist, J. K.: Intermittent and elliptical inertial oscillations in the atmospheric boundary layer, J. Atmos. Sci., 60, 2661-2673, 2003.

Mahrt, L.: Stratified atmospheric boundary layers, Bound.-Layer Meteor., 90, 375-396, 1999.

Malcher, J., and Kraus, H.: Low-level jet phenomena described by an integrated dynamical PBL model. Bound.-Layer Meteor., 27, 327-343, 1983.

May, P. T.: The Australian nocturnal jet and diurnal variations of boundary-layer winds over Mt. Isa in north-eastern Australia, Quart. J. Roy. Meteor. Soc., 121, 987-1003, 1995.

Monna, W. A. A.: On the use of wind profilers in meteorology, Ann. Geophys., 12, 482-486, 1994.
Pérez, I. A., Sánchez, M. L., García, M. A., and López, M. J.: Profiles of wind speed and temperature in the low atmosphere, Proc. 3rd Int. Conf. on Experiences with Automatic Weather Stations. Torremolinos, Málaga, Spain, Ministerio de Medio Ambiente, NIPO 310-03-003-0, www.inm.es, 2003.

Pérez, I. A., García, M. A., Sánchez, M. L., and de Torre, B.: Autocorrelation analysis of meteorological data from a RASS sodar, J. Appl. Meteor., 43, 1213-1223, 2004.

Peters, G. and Kirtzel, H. J.: Complementary wind sensing techniques: sodar and RASS, Ann. Geophys., 12, 506-517, 1994.

Simpson, J. E.: Sea Breeze and Local Wind. Cambridge University Press, Cambridge, 1994.

Stull, R. B.: An Introduction to Boundary Layer Meteorology, Kluwer Academic Publishers, Dordrecht, 1988.

Thorpe, A. J., and Guymer, T. H.: The nocturnal jet, Quart. J. Roy. Meteor. Soc., 103, 633-653, 1977.

Wölfelmaier, F. A., King, C. W., Mursch-Radlgruber, E., and Rengarajan, G.: Mini-sodar observations of drainage flows in the Rocky Mountains, Theor. Appl. Climatol., 64, 83-91, 1999. 